\title{
Effects of Intraspecific Competition and Host-Parasitoid Developmental Timing on Foraging Behaviour of a Parasitoid Wasp
}

\author{
Christelle Couchoux • Saskya van Nouhuys
}

Revised: 21 September 2013 / Accepted: 23 September 2013 /

Published online: 22 October 2013

(C) The Author(s) 2013. This article is published with open access at Springerlink.com

\begin{abstract}
In a context where hosts are distributed in patches and susceptible to parasitism for a limited time, female parasitoids foraging for hosts might experience intraspecific competition. We investigated the effects of host and parasitoid developmental stage and intraspecific competition among foraging females on host-searching behaviour in the parasitoid wasp Hyposoter horticola. We found that H. horticola females have a pre-reproductive adult stage during which their eggs are not mature yet and they forage very little for hosts. The wasps foraged for hosts more once they were mature. Behavioural experiments showed that wasps' foraging activity also increased as host eggs aged and became susceptible to parasitism, and as competition among foraging wasps increased.
\end{abstract}

Keywords Egg load·egg parasitoid Hyposoter horticola $\cdot$ Melitaea cinxia $\cdot$ ovigeny resource value

\section{Introduction}

Parasitoids demonstrate well the link between foraging behaviour (searching for hosts) and fitness because each egg laid in a host represents a fitness increase for the parasitoid (until Lack's clutch size is reached (Lack 1947)) . Therefore, they are often used to test predictions of optimal foraging theory (Hubbard and Cook 1978; Stephens and Krebs 1986; Wajnberg et al. 2006). But host-parasitoid interactions are complex and a number of parameters must be taken into account to determine the optimal foraging strategy (Mills and Wajnberg 2008; Corley et al. 2010). Factors

\footnotetext{
C. Couchoux $(\bowtie) \cdot$ S. van Nouhuys

Metapopulation Research Group, Department of Biosciences,

University of Helsinki, PO Box 65, Viikinkaari 1, 00014 Helsinki, Finland

e-mail: christelle.couchoux@gmail.com

S. van Nouhuys

Department of Ecology and Evolutionary Biology,

Cornell University, Ithaca, NY, USA
} 
influencing parasitoid foraging behaviour include individual physiological state, competition with conspecifics or other species, and host quality. The effects of those factors interact with each other, increasing the complexity of optimal foraging strategies.

There is a strong relationship between physiological state of a parasitoid and its hostsearching behaviour (Chan and Godfray 1993; Heimpel and Collier 1996). One important component of the physiological state of a parasitoid is egg load, which has been shown to have an impact on parasitoid foraging behaviour (Heimpel and Rosenheim 1995; Heimpel et al. 1998; Babendreier and Hoffmeister 2002; Burger et al. 2004; Hardy et al. 2013). Parasitoid egg production strategies such as resource allocation, total number of eggs produced, number that are mature at a time, presence of a pre-reproductive adult stage, and capacity to reabsorb eggs vary greatly among parasitoid species and depend on a number of life-history traits such as body size, longevity, egg size, clutch size, and host use type (idiobiont/koinobiont) (Jervis et al. 2001, 2008). Parasitoids can be categorized according to the maturity of their eggs at adult emergence; pro-ovigenic wasps emerge as adults with all their eggs mature, whereas in synovigenic wasps (most parasitoids) only a fraction of the eggs are mature at the beginning of the adult life (Jervis et al. 2001). In parasitoids egg load is an important life history trait because egg production is costly, but egg limitation can be a constraint on lifetime reproductive success (Weisser et al. 1997; Heimpel et al. 1998; Ellers et al. 2000).

A second factor that may influence parasitoid foraging behaviour is competition for hosts. Competition occurs when an individual decreases the fitness of another by increasing its own fitness while exploiting a common resource (Grover 1997). Competition may occur among conspecifics or between individuals of different species. Limited availability can be temporal or spatial and can concern a great diversity of resources such as food, space, cover, territory, or mates. Resource competition can be indirect, when one individual depletes the resource patch before another individual arrives, as in exploitation competition. Or it can be direct interference competition, which may be resolved through contests. These contests are mostly ritualized non-injurious agonistic behaviours (Maynard Smith and Parker 1976; Briffa and Sneddon 2010; Kokko 2013).

In parasitoids, larvae can compete for space and food (Brodeur and Boivin 2004), adults can experience local mate competition at emergence (Hamilton 1967) and also, since the distribution of hosts is usually aggregative (Godfray 1994; Wajnberg 2006), foraging adult females may face direct competition for hosts (Godfray 1994; Hardy et al. 2013). Intraspecific competition then occurs when several individual parasitoids of the same species exploit or attempt to exploit the same resource patch, sometimes at the same time. The simultaneous presence of competitors in a host patch leads to interference competition (Godfray 1994; Goubault et al. 2005). Mathematical models predict that intraspecific direct competition can affect the strategies of wasps foraging for hosts (Hassell and Varley 1969; van Alphen 1988) and studies have shown that presence of competitors can lead to behavioural modifications (Field and Calbert 1998, 1999; Hardy et al. 2013).

In addition to the physiological state of the wasp and competition, host patch quality, in terms of patch area, number of hosts or proportion of healthy hosts, has been shown to affect parasitoid foraging strategies (studies reviewed in Wajnberg 2006). Hosts are vulnerable to parasitism for a limited time only so host quality, in terms of susceptibility to parasitism, varies over time. The hosts are of highest quality, most valuable, when they are susceptible to parasitism. However, even a resource that 
is not ready to be used still may have value, as it can provide information, such as the location of a potential host, to be used later by the foraging individual (Collett 2008).

In this paper we investigate causes of variation of behaviour of a parasitoid foraging for hosts, as it is related to developmental timing of both the parasitoid and its host, and direct intraspecific competition between adult females. The study species is the parasitoid wasp Hyposoter horticola (Gravenhorst) (Ichneumonidae: Campoplaginae), a solitary egglarval endoparasitoid specialist of the Glanville Fritillary butterfly, Melitaea cinxia (Lepidoptera: Nymphalidae) (van Nouhuys and Ehrnsten 2004; Shaw et al. 2009). The butterflies lay clusters of 100-200 eggs on the underside of leaves of their host plants, Veronica spicata and Plantago lanceolata (Plantaginaceae) (Kuussaari et al. 2004). Female $H$. horticola, attracted to $M$. cinxia eggs and plants upon which egg clusters have been laid (Castelo et al. 2010), forage for these host egg clusters to parasitize.

Depending on the timing of their own egg production, H. horticola individuals may not search for hosts with equal intensity through their entire adulthood. A prereproductive phase might delay the foraging period of the wasps. Therefore in this study we addressed the developmental timing of the parasitoid measured as its own egg maturity and number.

The reproductive success of parasitoids is generally thought of as limited by the number of eggs produced and the time available for foraging (Ellers et al. 2000). In this particular system, the host is only susceptible to parasitism for a very short time just before it hatches from the eggshell (van Nouhuys and Ehrnsten 2004; Montovan et al. in prep.). To overcome the limited time availability of the host, the female parasitoids learn the location of potential hosts before they are susceptible to parasitism. The wasps visit the hosts for up to 2 weeks before they start to become caterpillars inside the egg, which is when they can be parasitized (van Nouhuys and Kaartinen 2008). During the visits to the host clusters, the wasps probe the eggs with their ovipositor, pushing on the eggs, presumably to assess if the host has yet become suitable for parasitism. Though hosts are visited by foraging wasps even when they are not yet susceptible to parasitism, our hypothesis is that as host egg clusters age, their value increases and is the highest when they are susceptible to parasitism. This increase of host value over time could manifest as a modification of the wasps' foraging behaviour. We expect the wasps to become more interested (e.g. visit for longer, probe the eggs more often) as the host eggs mature. We considered developmental timing of the host as its change in quality (susceptibility) over time.

Monitoring potential hosts before they are susceptible to parasitism increases the time available for foraging, but it also intensifies competition among foraging females because the location of a host egg cluster is known by several wasps (van Nouhuys and Ehrnsten 2004; van Nouhuys and Kaartinen 2008). Here, the competitive interaction we investigate is the presence of multiple females at the same host patch.

\section{Material \& Methods}

\section{Biology of the Species}

The butterfly Melitaea cinxia, the host of the parasitoid Hyposoter horticola, lives as a metapopulation in the Åland islands, a Finnish archipelago situated in the Baltic Sea 
between Sweden and mainland Finland. The metapopulation persists in stochastic balance between extinctions and colonisations, with the butterfly occupying around 500 of the 4000 patches of suitable habitat in any given year (Hanski 2011). The butterflies lay clusters of 100-200 eggs on the underside of leaves of their host plants (Veronica spicata and Plantago lanceolata) (Plantaginaceae) (Kuussaari et al. 2004). The female $H$. horticola forage for these host egg clusters to parasitize (van Nouhuys and Ehrnsten 2004). The adult wasp parasitizes the host in June-July when it is close to hatching from the egg. As the parasitized caterpillar develops, the H. horticola larva remains inside its host through winter diapause. In the spring the parasitoid larva consumes the entire host caterpillar and pupates inside it, just before the host itself would have pupated (van Nouhuys and Hanski 2004).

\section{Parasitoid Maturity: Life History and Behaviour}

In order to understand the wasp lifetime egg load, we first studied the longevity of $H$. horticola. Then, to quantify the reproductive timing and potential of the wasp through its lifetime, we recorded the number of mature eggs in the wasps' ovaries from 0 to 43 days, and observed the foraging behaviour of young and old wasps.

\section{Adult Longevity}

Large variations in lifespan are observed in the parasitic Hymenoptera, from a few days to several months (Quicke 1997). In order to assess H. horticola females' longevity, we kept 25 female wasps under laboratory conditions until they died naturally. The wasps used for the experiment originated from parasitized M. cinxia larvae collected from the field in Åland, Finland. After emergence, the adult parasitoids were sexed and the females placed in Petri dishes. They were kept in a climate chamber under standard rearing conditions mimicking a natural temperature (ranging from $10{ }^{\circ} \mathrm{C}$ at night to $18{ }^{\circ} \mathrm{C}$ during the day) and light cycle, and fed honey water $(1: 3)$ on cotton every other day.

\section{Wasps' egg Load Over Time}

As adults, different species of parasitoids carry a different number of eggs depending on their size, phenology, or other aspects of their physiology (Godfray 1994). To investigate the egg load and existence of a pre-reproductive adult stage (during which the eggs are not yet mature) in H. horticola, we counted the number of mature eggs in wasps from age 0 , just after emerging from the host as adults, until day 43, when they are well into there active adult lifetime. The wasps used for the experiment also originated from parasitized larvae collected from the field. The wasps were kept as described above (see Adult longevity methods). In total we analysed 210 wasps. 12 individuals were frozen $\left(-20^{\circ} \mathrm{C}\right)$ every 2 days starting at day 0 , until day 28 , after which 28 more wasps, aged 27 to 43 days were frozen at less regular intervals. Wasps that died naturally were also frozen and included in the study. We dissected the ovaries and oviducts under the microscope, spread the eggs out, and photographed them. We then used the count function in Adobe ${ }^{\circledR}$ Photoshop ${ }^{\circledR}$ to count the number of mature (fully developed) eggs in each female. 


\section{Wasps' Foraging Behaviour According to Their Age}

To test the hypothesis that young wasps behave differently than older wasps when foraging for hosts, we carried out a behavioural experiment in the laboratory comparing behaviour of young and old wasps on host egg clusters. We used egg clusters from laboratory-reared M. cinxia. The laboratory colony is mixed with one third of caterpillars from the field every year to ensure maintenance of genetic diversity and high fitness of the butterflies. The parasitoids came form parasitized $M$. cinxia larvae collected in the field and from egg clusters from laboratory-reared butterflies parasitized in the field.

The behavioural experiment consisted of introducing a female $H$. horticola in a mesh cage ( 40 by 40 by $50 \mathrm{~cm}$ ) containing a potted host plant on which a butterfly had laid an egg cluster. We observed and recorded if and for how long a wasp probed the eggs with its ovipositor. We used intermediate aged butterfly eggs (7-8 days old) that were not yet susceptible to parasitism but old enough that the wasps would actively probe them (see 'Parasitoid foraging behaviour' below). The wasps were classified as young ( $1-3$ days, $N=16$ ) and old (14-18 days, $N=18)$. In the field, it is normal for a host egg cluster to be visited multiple times by different wasps during the 2 weeks before it is susceptible to parasitism (van Nouhuys and Ehrnsten 2004; van Nouhuys and Kaartinen 2008), therefore we used the same egg cluster for testing the behaviour of several wasps. Additionally, Hyposoter horticola is known to deposit a mark that deters conspecifics, but only after it parasitized the eggs (Couchoux $\mathrm{C}$, Seppä P, van Nouhuys S (in prep.-a) Effectiveness of deterrent marking by a parasitoid wasp: behavioural and genetic approaches). In this experiment, host eggs were not yet susceptible to parasitism; therefore a wasp's visit is unlikely to have modified the host value.

\section{Parasitoid Foraging Behaviour According to Host Egg Age and Competition}

We tested the effect of host value and presence of competitors by carrying out a behavioural experiment in which we observed and recorded wasps' foraging behaviour at host egg clusters of differing maturity. Data for this experiment were collected in June 2009 and June-July 2010. Two potted host plants (Veronica spicata) with butterfly egg clusters of different maturity on each were set in a $30 \times 30 \times 3 \mathrm{~m}$ outdoor cage that simulates a host habitat patch (as used in van Nouhuys and Kaartinen 2008). We used young ( $3-5$ days old) and intermediate (7-9 days old) eggs in two trials, and young and susceptible (12-13 days old) eggs in one trial. In each trial, one to three host clusters were used for each egg age category. Because the time during which the eggs are susceptible is short, using susceptible eggs in the experiment was difficult and so only one trial was conducted.

In this experiment, we used egg clusters from the laboratory-reared butterflies and parasitoids from egg clusters of laboratory-reared butterflies parasitized in the field. In order to identify the wasps individually, we marked them with two dots of paint on the back of the thorax (notum). Carbon dioxide is commonly used to anaesthetize insects for research. However, some studies have shown negative effects of exposure to $\mathrm{CO}_{2}$ on behaviour (Nilson et al. 2006; Champion de Crespigny and Wedell 2008). So, as a precaution, we conducted a small-scale study. We marked 18 of the wasps 
(9 in trial 2 and 9 in trial 3) using $\mathrm{CO}_{2}$. The remaining wasps were marked at $8{ }^{\circ} \mathrm{C}$. This cold temperature, similar to what the wasps experience during the night under natural conditions, does not induce narcosis but renders the wasps less active, enabling us to mark them. We then compared the behaviour in the experiment of wasps that had been marked in the cold to that of wasps marked with $\mathrm{CO}_{2}$.

The individually marked female $H$. horticola were released in the cage ( $N=105$ over the three trials) where we continuously observed and recorded their visits to both plants from approximately 9 am to $6 \mathrm{pm}$, which encompasses the period of time that the wasps are active in a day (van Nouhuys and Kaartinen 2008). Because of limited availability, only 24 wasps were released in the first trial, while respectively 41 and 40 were released in the second and third trials. Each trial lasted about 2 days. The experiments did not last longer because of strong predation of the parasitoids by spiders.

We used The Observer ${ }^{\circledR}$ (version 9; Noldus Information Technology, Wageningen, The Netherlands) to record the wasps' behaviours during their visits to the plants (Table 1). In the analysis, 'visit' refers to the whole time a wasp was observed on or around a plant, and includes all of the behaviours listed. A visit starts when a wasp arrives at the plant (or 'around' the plant) and ends when the wasp has been away (out of the observer's field of view) for $5 \mathrm{~min}$. Competition occurs when more than one wasp was present during a visit. The data collected and analysed are visit duration, presence and duration of probing, presence of competition and presence of fights.

\section{Statistical Analyses}

All statistical analyses, except when stated otherwise, were performed with the statistical software R (R Core Team 2012). We mainly used generalized linear mixed models with, accordingly, a binomial distribution and logit link function or a Poisson distribution and log link function (glmmPQL, package 'MASS' (Venables and Ripley 2002)).

For the analysis of egg load over time, we used the mathematical software MATLAB ${ }^{\circledR}$ (MathWorks, Inc., Natick, Massachusetts, USA) with the Optimization Toolbox $^{\mathrm{TM}}$ to fit a bi-linear regression to the egg load data and identify the transition point of egg development rate.

In the laboratory experiment comparing the behaviour of young and mature wasps, we used the same egg cluster for testing the behaviour of several wasps. Therefore,

Table 1 List of behaviours observed and recorded with The Observer during a wasp's visit to the plant

\begin{tabular}{ll}
\hline Behaviour & Description \\
\hline Probing & Probing the egg cluster using the ovipositor \\
On eggs & Walking on and around the egg cluster but not probing \\
On plant & Walking or standing on the plant leaves but not on the egg cluster \\
Around & On the immediately surrounding vegetation, within the observer's field of view $(\sim 1 \mathrm{~m})$ \\
Competition & More than one wasp is present during a visit \\
Fight & Antagonistic interaction between wasps at the egg cluster
\end{tabular}


we included egg cluster identity (ID) and wasp rank number as random effects in the generalized linear mixed models comparing the proportion of visits in which the wasps probed and the duration of the probing between the two wasp age categories.

For the comparison of presence of competition during a visit, we used a generalized linear mixed model with host egg cluster age (young, intermediate, susceptible) as a fixed effect, and egg cluster ID and wasp ID as random effects. Visit duration, presence of probing and duration of probing were analysed using generalized linear mixed models with host egg cluster age, competition and the interaction as fixed effects, and egg cluster ID and wasp ID as random effects.

Finally, the effect of $\mathrm{CO}_{2}$ on wasps' behaviour was analysed with chi squared tests for whether or not the wasps were observed after the release (present in the experiment) and the presence of probing during the visits. $T$ tests were used to compare duration of both the visits and probing.

\section{Results}

Parasitoid maturity: life history and behaviour

\section{Adult longevity and egg load over time}

Under laboratory conditions, female $H$. horticola survived on average $41 \pm 13$ days, their lifespan ranging from 18 to 58 days. The number of mature eggs in the wasp ovaries and oviducts (egg load) varied over time, increasing as the wasp aged $\left(\mathrm{R}^{2}=0.59\right)$. A bilinear fit showed that the number of eggs increased rapidly (50 eggs/day) until the transition point at 10.7 days, after which it increased only slightly ( 2 eggs/day) over the next few weeks (Fig. 1). The transition point represents the end of the period of rapid egg maturation, after which the number of mature eggs does not significantly increase further. The wasps aged 12-43 days had on average $557 \pm 193$ eggs.

\section{Wasps' foraging behaviour according to their age}

There was a trend suggesting that the young wasps tended to probe host egg clusters less often (in $44 \%$ of the observations) than the old wasps ( $67 \%$ of the observations), but this difference was not significant $\left(\mathrm{F}_{(1,28)}=0.01, p=0.94\right)$. However, the young wasps that did probe clearly did so for a significantly shorter time than did the older wasps (young $=1 \min \pm 40 \mathrm{~s}$, old $=15 \min \pm 8 \min . \mathrm{F}_{(1,19)}=9.75, p=0.0075$ ).

Parasitoid foraging behaviour according to host egg age and competition

In each of the three trials, approximately half of the wasps released were observed visiting the eggs (totalling 52 out of 105). The data collected during the entire experiment amounts to 164 individual visits, representing $27 \mathrm{~h} 50 \mathrm{~min}$ of recorded behaviours. Out of the wasps that visited more than once during a trial $(59 \%$ of all the wasps), $66 \%$ visited both plants. Because we had only one trial with young and susceptible eggs and two with young and intermediate eggs, less data were available 


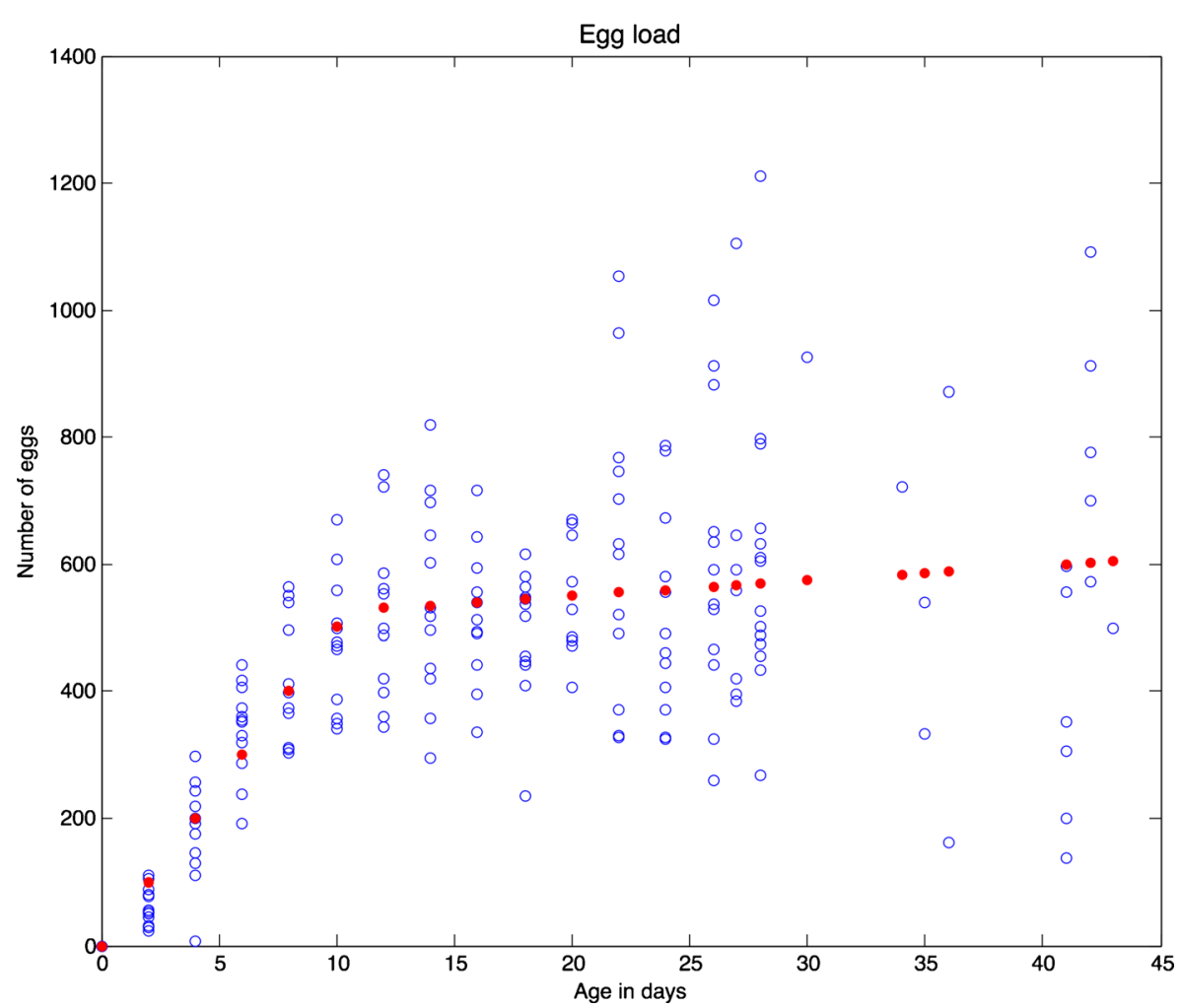

Fig. 1 Wasps' egg load from age 0 to 43. The blue open circles represent the individual wasps $(N=210)$, and the red full circles the bi-linear fit, with a transition point at 10.7 days

for susceptible eggs. In the three trials altogether, we recorded 72 visits to young eggs, 62 to intermediate eggs and 30 to susceptible eggs.

\section{Competition during a visit to a host egg cluster}

As the host eggs aged, competition between wasps became significantly more frequent $\left(\mathrm{F}_{(2,163)}=8.61, p=0.017\right)$. We observed competition in $15 \%$ of the visits to young eggs, and in $34 \%$ and $73 \%$ of the visits to intermediate aged eggs and susceptible eggs respectively (Fig. 2).

\section{Visits to the Egg Cluster Plants}

The duration of the wasps' visits to the plants with host egg clusters on them varied with both the age of the host eggs and the presence of competitors, while the interaction had no effect (Table 2). The wasps spent more time visiting the egg clusters as the eggs matured, and when competitors were present. Visits to susceptible eggs when there was competition were the longest and lasted for $36 \mathrm{~min} \pm 18 \mathrm{~min}$, while visits to young and intermediate eggs lasted around 4 min when there was no competition and 12-15 min when there was competition (Fig. 3). 


\section{Proportion of visits in which competitors were present}

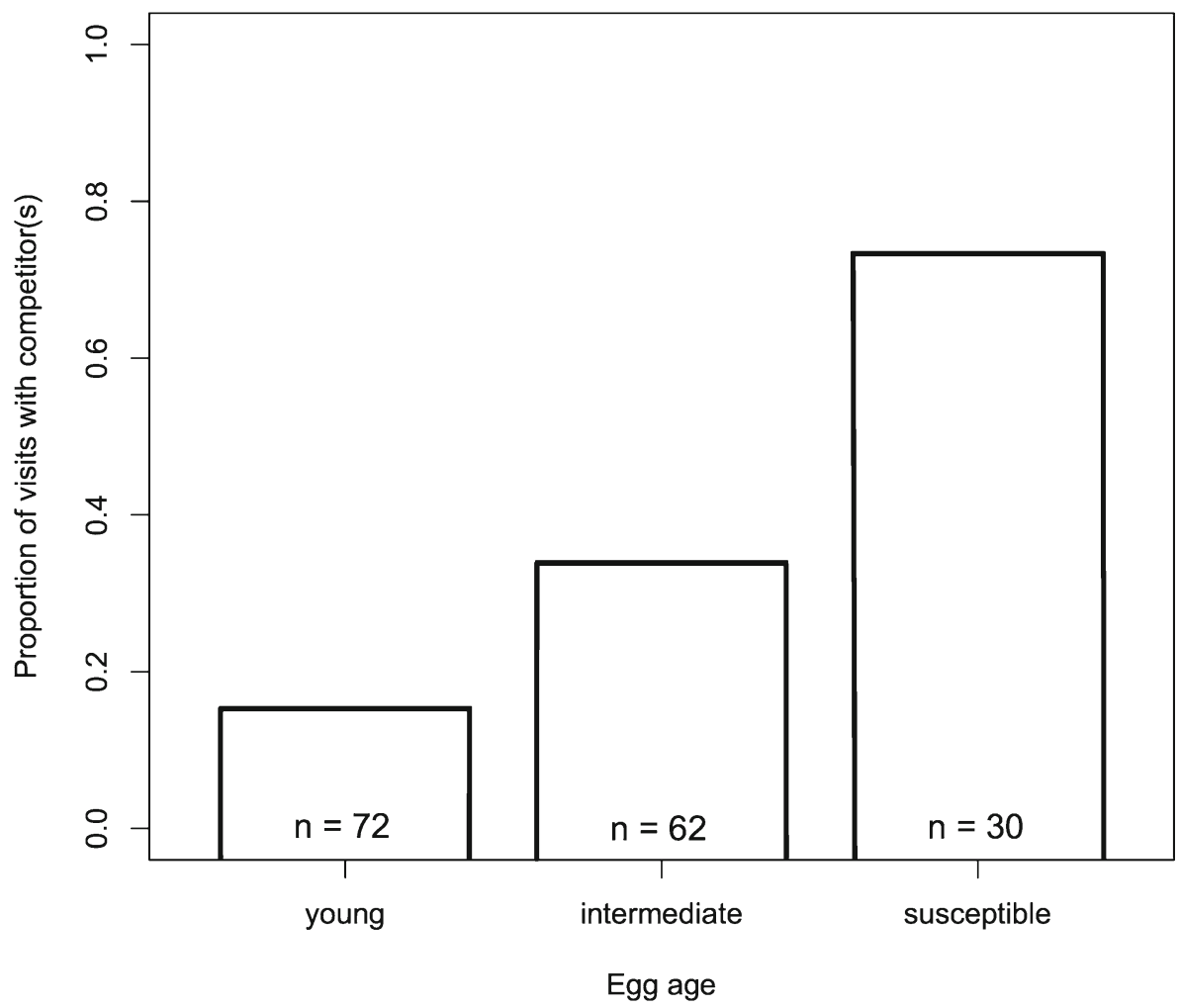

Fig. 2 Proportion of visits in which more than one wasp was present at young, intermediate and susceptible egg clusters

Table 2 Analysis of variance table for the generalized linear mixed models of visit duration, probing presence and probing duration. Host egg cluster ID and wasp ID are random effects. Significant $\mathrm{p}$-values are in bold

\begin{tabular}{llcc}
\hline & Df & $F$-value & $p$-value \\
\hline Visit duration & 163 & & \\
Egg age & 2 & 6.07 & $\mathbf{0 . 0 3 6 1}$ \\
Competition & 1 & 40.76 & $\mathbf{< . 0 0 0 1}$ \\
Egg age * competition & 2 & 1.03 & 0.3607 \\
Probing presence & 163 & & \\
Egg age & 2 & 1.61 & 0.2395 \\
Competition & 1 & 2.93 & 0.1668 \\
Egg age * competition & 2 & 5.53 & $\mathbf{0 . 0 0 6 6}$ \\
Probing duration & 72 & & \\
Egg age & 2 & 20.38 & $\mathbf{0 . 0 0 3 9}$ \\
Competition & 1 & 14.37 & $\mathbf{0 . 0 0 0 8}$ \\
Egg age * competition & 2 & 3.57 & $\mathbf{0 . 0 4 2 6}$ \\
\hline
\end{tabular}




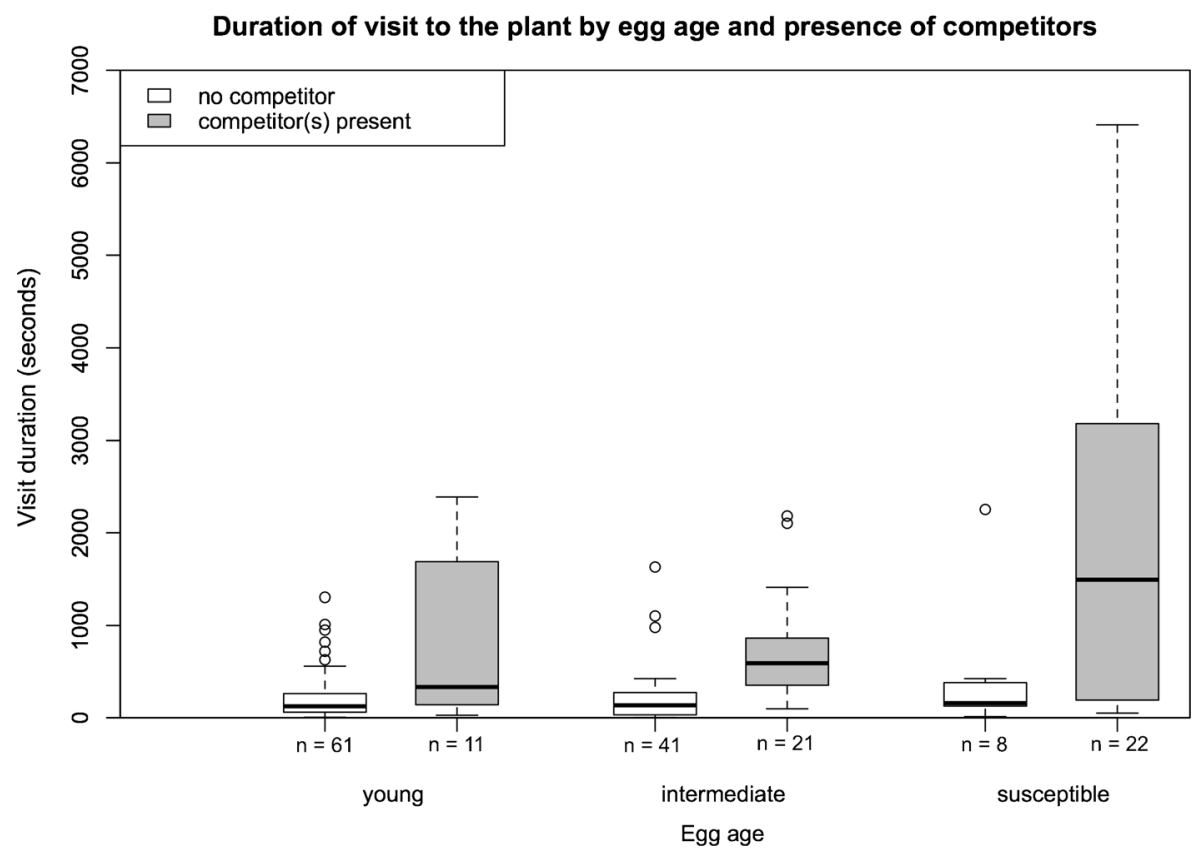

Fig. 3 Duration of visits to the plants with young, intermediate and susceptible egg clusters on them, in the absence of competition (open bars) and in presence of competition (grey bars)

\section{Probing the Host Egg Clusters}

Only the interaction of egg age and competition had a significant effect on the probability of the wasps probing the egg cluster (Table 2). The wasps probed the intermediate eggs more often when competitors were present (no competition: $34 \%$, competition: $90 \%$. Figure $4 a$.).

The amount of time the wasps spent probing increased with egg age and competition, the effect of which was stronger for susceptible eggs (Table 2). The wasps spent a long time $(15 \pm 5 \mathrm{~min})$ probing the susceptible eggs when there was competition while they spent only a couple of minutes probing the eggs in the five other groups (Fig. 4b).

\section{Fights Between Two Wasps Over a Host Egg Cluster}

During the observations we noticed that the wasps interacted directly with each other; jumping away when a conspecific landed close by and sometimes fighting over a host egg cluster. These fights were quite intense, involving the wasps rolling with each other and poking each other with their ovipositor. Although we did not have enough data to conduct a statistical analysis, all the fights we observed occurred during visits to susceptible eggs $(N=6)$.

\section{Marking Method}

We did not find a negative effect of $\mathrm{CO}_{2}$ on the behaviour of the foraging females. Wasps marked using $\mathrm{CO}_{2}$ anaesthesia, compared to wasps marked in the cold, were 


\section{a \\ Probing behaviour according to egg age and competition}

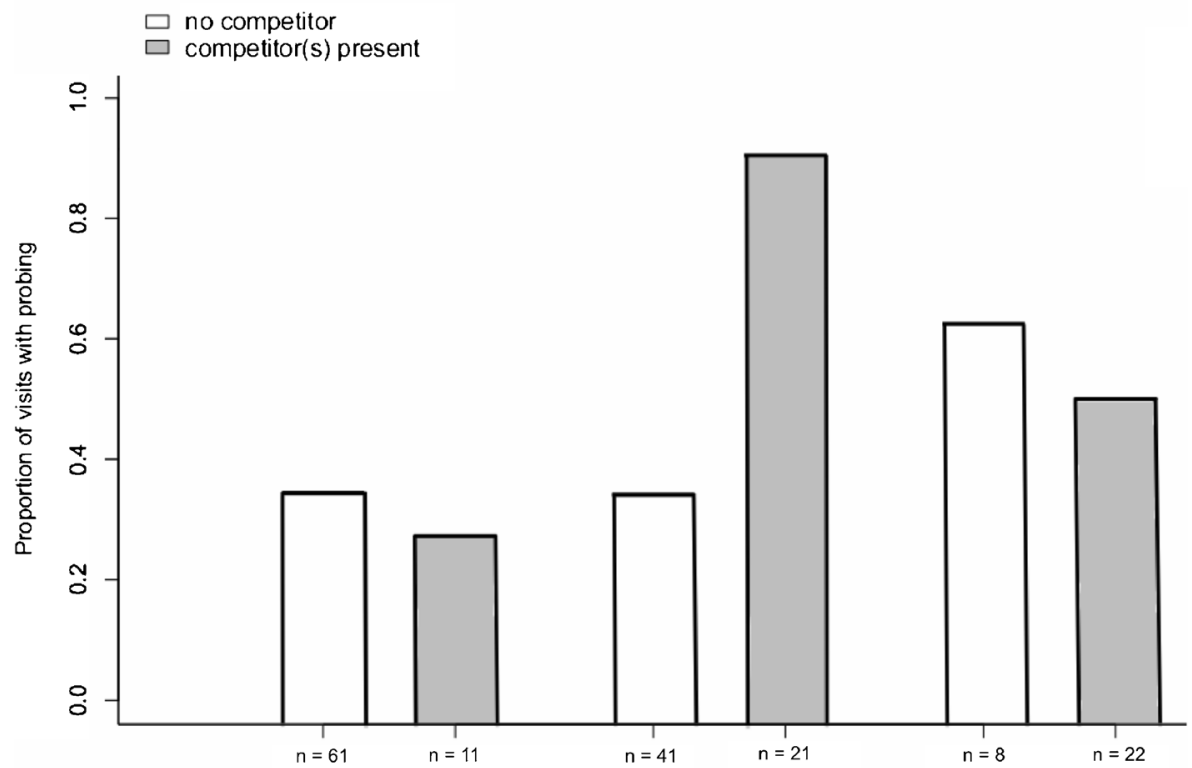

b

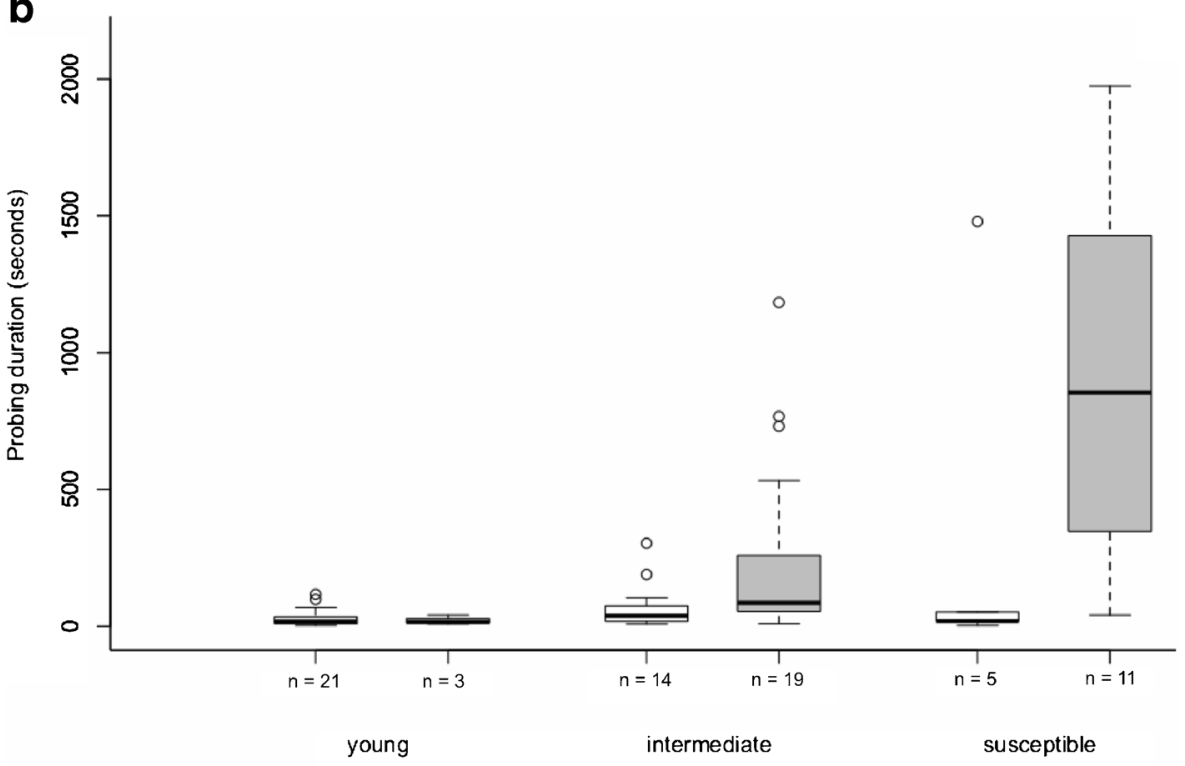

Egg age

Fig. 4 Proportion of visits in which the wasps probed the eggs (a.) and duration of the probing (b.) of young, intermediate and susceptible eggs, in the absence of competition (open bars) and in presence of competition (grey bars)

equally present in the experiment (Pearson's Chi squared test, $\chi^{2}=0.39, \mathrm{df}=1$, $p=0.53)$. They also visited plants for equal duration $\left(\mathrm{F}_{(1,70)}=0.17, p=0.68\right)$, probed 
as often (Pearson's Chi squared test, $\chi^{2}=0.50, \mathrm{df}=1, p=0.48$ ) and probed for equal duration $\left(\mathrm{F}_{(1,17)}=0.07, p=0.80\right)$. While we do not consider that the $\mathrm{CO}_{2}$ influenced the behaviour that we observed, we would not analyse the effect of $\mathrm{CO}_{2}$ on $\mathrm{H}$. horticola longevity because of the wasps' short lifespan in the outdoor cage due to high predation rate.

\section{Discussion}

In this study we examined the foraging behaviour of the parasitoid $H$. horticola, with respect to its maturity, host age and competition among foraging females. We found that $H$. horticola females have a pre-reproductive adult stage during which their eggs are not yet mature and they forage little for hosts. At maturity they have on average 550 eggs and forage actively for hosts. Behavioural experiments showed that, as the host eggs mature and become susceptible to parasitism and competition increases, the wasps modify their foraging behaviour, making more visits to and probing the host eggs clusters.

\section{Parasitoid Maturity: Life History and Behaviour}

When kept under laboratory conditions with unlimited food, female $H$. horticola live for about 6 weeks, which make them, compared to other parasitoids, a long-lived species (Quicke 1997). During the first few days of their adult life the wasps do not have any mature eggs. They increase their egg stock at a high rate during the first 10 days and then much more slowly through the rest of their life. With no mature eggs at emergence, $H$. horticola has an ovigeny index (the number of mature eggs carried at the start of adult life divided by the average lifetime potential fecundity (Jervis et al. 2001)) of 0 , making them extremely synovigenic. Their long lifespan and the fact that females $H$. horticola exhibit a pre-reproductive adult stage conform to studies of other parasitoid species showing a negative correlation between female lifespan and ovigeny index (Jervis et al. 2001; Jervis and Ferns 2004). Because of this pre-oviposition period, during the first days of their adulthood, the wasps are limited in the number of eggs they could lay (Ellers et al. 2000).

Having few mature eggs available for oviposition could explain why the young wasps forage for hosts and probe host eggs much less than do older individuals. To avoid egg limitation, the wasps may wait until they have accumulated a threshold number of mature eggs in their ovaries before actively foraging. However, this compulsory delay is not very detrimental since, under natural conditions, it occurs when the butterfly hosts start to emerge and oviposit, so only a few host egg clusters are susceptible to parasitism (van Nouhuys and Ehrnsten 2004).

As the wasps get older and produce more eggs, their foraging activity increases. A typical host egg cluster is 150 eggs and a wasp parasitizes only a fraction of the cluster (on average one third) (van Nouhuys and Ehrnsten 2004). A mature female has roughly 550 eggs so can in principal parasitize more than 10 egg clusters. However, taking into account the limited time the hosts are susceptible to parasitism (van Nouhuys and Kaartinen 2008; Montovan et al. in prep.), and the competition among foraging females, it is unlikely that an individual would have that many 
oviposition opportunities. We expect a female with a high reproductive success to parasitize only a few host clusters, and most of the females not to have access to reproduction at all (Couchoux C, Seppä P, van Nouhuys S (in prep.-b) Spatial genetic structure is less affected by habitat fragmentation in a parasitoid wasp than in its butterfly host, Couchoux C, Seppä P, van Nouhuys S (in prep.-c) Reproductive success of the parasitoid wasp Hyposoter horticola). Thus, once the wasps are reproductive they typically have more eggs than they can use.

Natural selection and behavioural plasticity have been shown to promote parasitoid egg load matching host availability (Price 1975; Charnov and Skinner 1984; Rosenheim 1996; Mangel and Heimpel 1998; Sevenster et al. 1998). An egg load such as that of $H$. horticola, that does not match the availability of hosts, would suggest that the wasps are not well adapted to the host. This is probably not the case since $H$. horticola is known only to use M. cinxia (Shaw et al. 2009). A possible explanation is that, over the past two decades since the population dynamics of the butterfly have been monitored in Alland, the density of $M$. cinxia has been relatively low and steady at the metapopulation scale (Hanski 2011). However in less fragmented landscapes such as in Estonia (Mattila et al. 2012), and historically even in Åland, the $M$. cinxia butterfly populations have been, at least anecdotally, larger and more dynamic (I. Hanski, personal communication). So, during some years, the wasps may have been able to lay many more eggs than they currently can. Perhaps past environmental stochasticity in the form of large fluctuations of the host population size could explain why the wasps exhibit an egg load, which under current conditions appears too high.

\section{Parasitoid Foraging Behaviour According to Host Egg Age and Competition}

\section{Foraging for Potential Hosts, Host Value}

We found that the wasps forage for young host eggs, and the intensity of foraging increased as the host eggs aged. These results support the idea that the host eggs have some value when they are young, and the value increases as they age and become closer to being susceptible to parasitism. Thus, female $H$. horticola not only forage for actual resources, hosts susceptible to parasitism, but also for potential resources that are not yet ready to be parasitized (young and intermediate aged eggs in our experiment). Hyposoter horticola is not the only species to forage for resources not yet ready to be exploited (Collett 2008). For example, in some butterfly species of the genus Heliconius, males are attracted by sex pheromones emitted by female pupae. The males perch, typically several on a pupa, and compete to mate with the females as soon as they emerge (Brown 1981).

While visiting hosts that are not ready to be used is important for keeping track of the locations of potential hosts (van Nouhuys and Kaartinen 2008) and possibly their maturity level, susceptible hosts are presumably more valuable for the foraging wasps as they provide an immediate fitness gain.

Parasitoid foraging behaviour is commonly studied as the time a wasp spends foraging at a host patch (Wajnberg 2006). We used the duration of the wasp's visit to the plant as a 'patch residence time', but, because of the specifics of our system (female $H$. horticola forage for both actual and potential resources), we also included 
the probing of the host eggs, an important behaviour. The probing behaviour exhibited by $H$. horticola may be a way for the wasp to assess the host value by checking if they are able, mechanically, to parasitize the host eggs. Indeed, it is possible that the wasps can only parasitize the hosts when the eggs are about to hatch. At that time the eggshell may become thin enough for the parasitoid ovipositor to puncture a hole. Probing behaviour, by its presence and duration, reflects how actively a wasp is foraging for hosts.

We found that the wasps modified their behaviour according to host maturity, visiting more and investing more time in foraging activities as the host eggs aged and increased in value. These results are in agreement with a number of studies, reviewed in Wajnberg 2006, that show, as predicted by the marginal value theorem (Charnov 1976), that patch residence time of foraging parasitoids increases with patch quality in terms of patch surface area, number of hosts or proportion of healthy hosts. However in this study host quality increases over time.

\section{Effect of Competition on Foraging Behaviour}

In the Åland islands, the butterfly M. cinxia is attacked by H. horticola and three other parasitoids species of which one attacks larvae and two attack pupae (Lei et al. 1997; van Nouhuys and Hanski 2005). Hyposoter horticola is the only one that forages for eggs and therefore adult females do not suffer from exploitation competition since they parasitize the hosts at the earliest stage. However, H. horticola suffer from intraspecific direct competition when several foraging females attempt to parasitize the same host cluster. Because the wasps visit the same host egg clusters repeatedly, sometimes several times in a day, the probability of several wasps being at a cluster at the same time is relatively high.

Laboratory and field studies of parasitoids have shown that they tend to aggregate in patches of high quality, such as high host-density patches, which creates intraspecific direct competition at the host patch level (Waage 1983; Summy et al. 1985; Smith and Maelzer 1986; Vanbergen et al. 2007). In this system, host egg maturity can be considered as host quality, and has an effect on the number of wasps observed on the plant at the same time. Competition becomes more frequent as the hosts age and become more valuable, and is maximal when the hosts are susceptible to parasitism.

It should be noted that the observed increase in competition as the hosts age is not simply explained by the fact that as the hosts age and wasps visit for longer, the probability of co-occurrence of two wasps increases. Indeed, visits at young and intermediate eggs were the same duration but competition was higher at intermediate eggs. Also, at susceptible eggs, visits without competition were long enough that two wasps visiting at the same time could have occurred. On average, visits when there was no competition were shorter but their durations overlapped with those of visits with competition, and a large fraction of time no wasps were present.

We found that in the presence of conspecifics, $H$. horticola visited the plant for longer, probed intermediate eggs more often and probed host eggs for longer than when they were alone. Other studies have also shown that intraspecific direct competition can affect parasitoid foraging behaviour (Field and Calbert 1998, 1999; Hardy et al. 2013). The direction of this effect depends on whether competitors 
interfere with each other or not. If there is no interference, the marginal value theorem predicts that competition shortens patch residence time (van Alphen 1988). However, when the foraging wasps interfere, as is the case in our system, time spent in the patch should increase (Hassell and Varley 1969). Following this prediction, patch residence time has been shown to increase with competition in several other studies of parasitoid wasps (Visser et al. 1990; Visser et al. 1992; Sjerps and Haccou 1994; Ohno 1999; Haccou et al. 2003; Wajnberg et al. 2004; Goubault et al. 2005; Hardy et al. 2013; Stockermans and Hardy 2013).

Spending more time foraging at a cluster when there is competition, especially at a high value patch (eggs susceptible to parasitism), can be interpreted as playing a war of attrition (Maynard Smith 1974), and perhaps guarding the host cluster. Indeed, foraging female $H$. horticola do protect the host clusters they parasitize. After oviposition they deposit chemicals on the leaves surrounding the egg cluster that deter conspecifics from ovipositing there (Couchoux C, Seppä P, van Nouhuys S (in prep.-a) Effectiveness of deterrent marking by a parasitoid wasp: behavioural and genetic approaches). This behaviour is effective, but it seems that the mark is less respected when competition is high (Couchoux C, Seppä P, van Nouhuys S (in prep.a) Effectiveness of deterrent marking by a parasitoid wasp: behavioural and genetic approaches, Couchoux C, Seppä P, van Nouhuys S (in prep.-b) Spatial genetic structure is less affected by habitat fragmentation in a parasitoid wasp than in its butterfly host, Couchoux C, Seppä P, van Nouhuys S (in prep.-c) Reproductive success of the parasitoid wasp Hyposoter horticola). In this case, staying at the cluster when competitors are around and possibly directly interfering with conspecifics to protect the resource until it is no longer susceptible to parasitism (once the host eggs hatch) might be beneficial (Hardy et al. 2013).

Game theoretical models predict that the intensity of agonistic behaviours can escalate to dangerous fights when the resource is highly valuable (Maynard Smith and Parker 1976; Kokko 2013). Though our experiment was not specifically designed to study direct interactions between females, we observed some. Females probing the host eggs sometimes hopped away when another wasp landed close by, disrupting their foraging. We also observed more aggressive interactions, in the form of fights at susceptible eggs. Other solitary foraging parasitoids have been shown to interfere directly with conspecifics by fighting (Hardy and Blackburn 1991; Field and Calbert 1998; Shelly 1999; Wajnberg et al. 2004; Batchelor et al. 2005; Goubault et al. 2005; Hardy et al. 2013) and the perceived value of a resource has been shown to influence the outcome of contests, notably in the parasitoid Goniozus nephantidis (Humphries et al. 2006; Stockermans and Hardy 2013).

\section{Conclusion}

As a specialist parasitoid, $H$. horticola is well adapted to its host $M$. cinxia. The wasp phenology (when their eggs are mature) matches the host availability in the field. However it seems that they have more eggs than they need, perhaps because of recent changes in the magnitude of population dynamics of the host.

A particularity of these wasps is that they visit hosts even when the hosts are not yet susceptible to parasitism. Previous studies have shown that this is not simply a 
foraging error, but that they gain useful information from these visits (van Nouhuys and Ehrnsten 2004; van Nouhuys and Kaartinen 2008). Attending to potential resources has been shown in insects (Brown 1981; Collett 2008), but rarely in parasitoid wasps (Rosenheim 1987). Though they visit young host eggs, as the host eggs get closer to being susceptible and their value increases, the wasps forage more actively. Therefore in this system host maturity can be used as an indicator of host quality, but the hosts also clearly have some value when they cannot be parasitized.

Not only do wasps increasingly attend host eggs clusters as the host value increases, but they also spend more time at host egg clusters in the presence of conspecifics. During this time they interact antagonistically, and at least sometimes when the hosts are susceptible, they fight. Thus they exhibit contest competition for hosts.

Our study showed that parasitoid foraging behaviour could be affected by (1) wasps' egg load, the wasps foraging with less intensity when they have only few mature eggs, (2) host value, the wasps investigating hosts more actively as they get closer to being susceptible, and (3) intraspecific competition among foraging females, the wasps spending more time at the host cluster when conspecifics were present. Host-searching behaviours are complex, multiple factors such as forager's physiological state, resource value and intraspecific competition, as well as their interactions, should be integrated into conceptual and theoretical models of parasitoid foraging strategy.

Acknowledgements We would like to thank H. Aho, M. Brunfeldt, S. Ehonen, L. Heikkinen, S. Ikonen, T. Lahtinen, and K. Montovan for help in the field and laboratory, A. Ruina for help with the bi-linear fit of egg load data, the Academic Academy of Finland grants no 1255553, 213547, 250444 for financial support, and three anonymous reviewers whose comments helped improve the manuscript.

Open Access This article is distributed under the terms of the Creative Commons Attribution License which permits any use, distribution, and reproduction in any medium, provided the original author(s) and the source are credited.

\section{References}

Babendreier D, Hoffmeister TS (2002) Superparasitism in the solitary ectoparasitoid Aptesis nigrocincta: the influence of egg load and host encounter rate. Entomol Exp Appl 105:63-69

Batchelor TP, Hardy ICW, Barrera JF, Perez-Lachaud G (2005) Insect gladiators II: Competitive interactions within and between bethylid parasitoid species of the coffee berry borer, Hypothenemus hampei (Coleoptera : Scolytidae). Biol Control 33:194-202

Briffa M, Sneddon LU (2010) Contest Behavior. In: Westneat DF, Fox CW (eds) Evolutionary behavioral ecology. Oxford University Press, Oxford, pp 246-265

Brodeur J, Boivin G (2004) Functional ecology of immature parasitoids. Annu Rev Entomol 49:2749

Brown KS (1981) The biology of Heliconius and related genera. Annu Rev Entomol 26:427-456

Burger JMS, Hemerik L, van Lenteren JC, Vet LEM (2004) Reproduction now or later: optimal hosthandling strategies in the whitefly parasitoid Encarsia formosa. Oikos 106:117-130

Castelo MK, van Nouhuys S, Corley JC (2010) Olfactory attraction of the larval parasitoid, Hyposoter horticola, to plants infested with eggs of the host butterfly, Melitaea cinxia. J Insect Sci 10 
Champion de Crespigny FE, Wedell N (2008) The impact of anaesthetic technique on survival and fertility in Drosophila. Physiol Entomol 33:310-315

Chan MS, Godfray HCJ (1993) Host-feeding strategies of parasitoid wasps. Evol Ecol 7:593-604

Charnov EL (1976) Optimal foraging, Marginal Value Theorem. Theor Popul Biol 9:129-136

Charnov EL, Skinner SW (1984) Evolution of host selection and clutch size in parasitoid wasps. Fla Entomol 67:5-21

Collett TS (2008) Insect behaviour: learning for the future. Curr Biol 18:R131-R134

Corley JC, Villacide J, van Nouhuys S (2010) Patch time allocation by a parasitoid: the influence of conspecifics, host abundance and distance to the patch. J Insect Behav 23:431-440

Ellers J, Sevenster JG, Driessen G (2000) Egg load evolution in parasitoids. Am Nat 156:650-665

Field SA, Calbert G (1998) Patch defence in the parasitoid wasp Trissolcus basalis: When to begin fighting? Behaviour 135:629-642

Field SA, Calbert G (1999) Don't count your eggs before they're parasitized: contest resolution and the tradeoffs during patch defense in a parasitoid wasp. Behav Ecol 10:122-127

Godfray HCJ (1994) Parasitoids: behavioral and evolutionary ecology. Princeton University Press, Princeton

Goubault M, Outreman Y, Poinsot D, Cortesero AM (2005) Patch exploitation strategies of parasitic wasps under intraspecific competition. Behav Ecol 16:693-701

Grover JP (1997) Resource competition. Springer

Haccou P, Glaizot O, Cannings C (2003) Patch leaving strategies and superparasitism: an asymmetric generalized war of attrition. J Theor Biol 225:77-89

Hamilton WD (1967) Extraordinary sex ratios. Science 156:477

Hanski IA (2011) Eco-evolutionary spatial dynamics in the Glanville fritillary butterfly. Proc Natl Acad Sci 108:14397-14404

Hardy ICW, Blackburn TM (1991) Brood guarding in a bethylid wasp. Ecol Entomol 16:55-62

Hardy ICW, Goubault M, Batchelor TP (2013) Hymenopteran contests and agonistic behaviour. In: Hardy ICW, Briffa M (eds) Animal contests. Cambridge University Press

Hassell MP, Varley GC (1969) New inductive population models for insect parasites and its bearing on biological control. Nature 223:1133-1137

Heimpel GE, Collier TR (1996) The evolution of host-feeding behaviour in insect parasitoids. Biol Rev Camb Philos Soc 71:373-400

Heimpel GE, Mangel M, Rosenheim JA (1998) Effects of time limitation and egg limitation on lifetime reproductive success of a parasitoid in the field. Am Nat 152:273-289

Heimpel GE, Rosenheim JA (1995) Dynamic host feeding by the parasitoid Aphytis melinus - The balance between current and future reproduction. J Anim Ecol 64:153-167

Hubbard SF, Cook RM (1978) Optimal foraging by parasitoid wasps. J Anim Ecol 47:593-604

Humphries EL, Hebblethwaite AJ, Batchelor TP, Hardy ICW (2006) The importance of valuing resources: host weight and contender age as determinants of parasitoid wasp contest outcomes. Anim Behav 72:891-898

Jervis MA, Ellers J, Harvey JA (2008) Resource acquisition, allocation, and utilization in parasitoid reproductive strategies. Annu Rev Entomol 53:361-385

Jervis MA, Ferns PN (2004) The timing of egg maturation in insects: ovigeny index and initial egg load as measures of fitness and of resource allocation. Oikos 107:449-460

Jervis MA, Heimpel GE, Ferns PN, Harvey JA, Kidd NAC (2001) Life-history strategies in parasitoid wasps: a comparative analysis of 'ovigeny'. J Anim Ecol 70:442-458

Kokko H (2013) Dyadic contests: modeliing fights between two individuals. In: Hardy ICW, Briffa M (eds) Animal contests. Cambridge University Press

Kuussaari M, van Nouhuys S, Hellmann J, Singer MC (2004) Larval biology of checkerspot butterflies. In: Ehrlich PR, Hanski I (eds) On the wings of checkerspots: a model system for population biology. Oxford University Press, pp 138-160

Lack D (1947) The significance of clutch size. Ibis 89:302-352

Lei GC, Vikberg V, Nieminen M, Kuussaari M (1997) The parasitoid complex attacking the Finnish populations of Glanville fritillary Melitaea cinxia (Lep: Nymphalidae), an endangered butterfly. J Nat Hist 31:635-648

Mangel M, Heimpel GE (1998) Reproductive senescence and dynamic oviposition behaviour in insects. Evol Ecol 12:871-879 
Mattila ALK, Duplouy A, Kirjokangas M, Lehtonen R, Rastas P, Hanski I (2012) High genetic load in an old isolated butterfly population. Proc Natl Acad Sci U S A 109:E2496-E2505

Maynard Smith J (1974) The theory of games and the evolution of animal conflicts. J Theor Biol 47:209221

Maynard Smith J, Parker GA (1976) Logic of asymmetric contests. Anim Behav 24:159-175

Mills NJ, Wajnberg E (2008) Optimal foraging behavior and efficient biologial control. In: Wajnberg E, Bernstein C, van Alphen JJM (eds) Behavioral ecology of insect parasitoids. Blackwell, Oxford, pp 3-30

Montovan K, Couchoux C, Reeve K, van Nouhuys S (in prep.) The puzzle of sub-maximal resource use by a parasitoid wasp

Nilson TL, Sinclair BJ, Roberts SP (2006) The effects of carbon dioxide anesthesia and anoxia on rapid cold-hardening and chill coma recovery in Drosophila melanogaster. J Insect Physiol 52:1027-1033

Ohno K (1999) Brood guarding in Trissolcus basalis (Watanabe) (Hymenoptera: Scelionidae), an egg parasitoid of the brown- winged Green Bug, Plautia crossata stali Scott (Heteroptera: Pentatomidae). Entomol Sci:41-47

Price PW (1975) Reproductive strategies of parasitoids. In: Price PW (ed) Evolutionary Strategies of Parasitic Insects and Mites. Plenum, New York, pp 87-111

Quicke DLJ (1997) Parasitic Wasps. Chapman and Hall, London

R Core Team (2012) R: A language and environment for statistical computing. R Foundation for Statistical Computing, Vienna, ISBN 3-900051-07-0, URL http:/www.R-project.org/

Rosenheim JA (1987) Host location and exploitationby the cleptoparasitic wasp Argochrysis armilla - The role of learning (Hymenoptera, Chrysididae). Behav Ecol Sociobiol 21:401-406

Rosenheim JA (1996) An evolutionary argument for egg limitation. Evolution 50:2089-2094

Sevenster JG, Ellers J, Driessen G (1998) An evolutionary argument for time limitation. Evolution 52:1241-1244

Shaw MR, Stefanescu C, van Nouhuys S (2009) Parasitoids of European butterflies. In: Settele J, Shreeve TG, Konvicka M, Van Dyck H (eds) Ecology of butterflies in Europe. Cambridge University Press, Cambridge, pp 130-156

Shelly TE (1999) Defense of oviposition sites by female oriental fruit flies (Diptera : Tephritidae). Fla Entomol 82:339-346

Sjerps M, Haccou P (1994) Effects of competition on optimal patch leaving - a war of attrition. Theor Popul Biol 46:300-318

Smith ADM, Maelzer DA (1986) Aggregation of parasitoids and density-independence of parasitism in field populations of the wasp Aphytis melinus and its host, the red scale Aonidiella aurantii. Ecol Entomol 11:425-434

Stephens DW, Krebs JR (1986) Foraging theory. Princeton University Press, Princeton

Stockermans BC, Hardy ICW (2013) Subjective and objective components of resource value additively increase aggression in parasitoid contests. Biol Lett 9

Summy KR, Gilstrap FE, Hart WG (1985) Aleurocanthus woglumi (Hom, Aleyrodidae) and Encarsia opulenta (Hym, Encyrtidae) density-dependent relationship between adult parasite aggregation and mortality of the host. Entomophaga 30:107-112

van Alphen JJM (1988) Patch-time allocation by insect parasitoids: superparasitism and aggregation. In: de Jong G (ed) Population genetics and evolution. Springer, pp 216-221

van Nouhuys S, Ehrnsten J (2004) Wasp behavior leads to uniform parasitism of a host available only a few hours per year. Behav Ecol 15:661-665

van Nouhuys S, Hanski I (2004) Natural enemies of checkerspot butterflies. In: Ehrlich PR, Hanski I (eds) On the wings of checkerspots: a model system for population biology. Oxford University Press, Oxford, pp 161-180

van Nouhuys S, Hanski I (2005) Metacommunities of butterflies, their host plants and their parasitoids. In: Holyoak M, Leibold MA, Holt RD (eds) Metacommunities: spatial dynamics and ecological communities. University of Chicago Press, Chicago, pp 99-121

van Nouhuys S, Kaartinen R (2008) A parasitoid wasp uses landmarks while monitoring potential resources. Proc Roy Soc B-Biol Sci 275:377-385

Vanbergen AJ, Jone TH, Hail RS, Watt AD, Elston DA (2007) Consequences for a host-parasitold interaction of host-plant aggregation, isolation, and phenology. Ecol Entomol 32:419-427

Venables WN, Ripley BD (2002) Modern applied statistics with S, 4th edn. Springer, New York 
Visser ME, van Alphen JJM, Hemerik L (1992) Adaptive superparasitism and patch time allocation in solitary parasitoids - an ESS model. J Anim Ecol 61:93-101

Visser ME, van Alphen JJM, Nell HW (1990) Adaptive superparasitism and patch time allocation in solitary parasitoids - the influence of the number of parasitoids depleting a patch. Behaviour 114:21-36

Waage JK (1983) Aggregation in field parasitoid populations - foraging time allocation by a population of diadegma (hymenoptera, ichneumonidae). Ecol Entomol 8:447-453

Wajnberg E (2006) Time allocation strategies in insect parasitoids: from ultimate predictions to proximate behavioral mechanisms. Behav Ecol Sociobiol 60:589-611

Wajnberg E, Bernhard P, Hamelin F, Boivin G (2006) Optimal patch time allocation for time-limited foragers. Behav Ecol Sociobiol 60:1-10

Wajnberg E, Curty C, Colazza S (2004) Genetic variation in the mechanisms of direct mutual interference in a parasitic wasp: consequences in terms of patch-time allocation. J Anim Ecol 73:1179-1189

Weisser WW, Volkl W, Hassell MP (1997) The importance of adverse weather conditions for behaviour and population ecology of an aphid parasitoid. (vol 66, pg 386, 1997). J Anim Ecol 66:780 